\title{
Eastern African Quaternary Climate change and variability
}

\author{
Christine A. Ogola \\ Nanyuki, Kenya, 23-27 July 2013
}

The fourth Eastern Africa Quaternary Research Nanyuki near Mt. Kenya and was hosted by National Museums of Kenya. It was attended by 55 delegates from 14 countries and co-sponsored by the National Museums of Kenya (NMK), the International Union for Quaternary Research (INQUA), the Embassy of France (Nairobi), the French Institute for Research and Development (IRD) and PAGES.

Then Director General NMK, Idle Omar Farah and INQUA President Margaret Avery graciously attended the opening ceremony. Dr Farah, delighted to host the conference, stressed the commitment of NMK to capacity building of scientists and communities from areas with good natural archives of past environmental change. He also noted that EAQUA members' research dealt with relevant global issues such as climate change and adaptation, and encouraged the participants to make use of the immense paleoecological, geological and cultural records at NMK for their research. Finally, he briefly outlined how NMK was streamlining the processes for Quaternary research in Kenya. Dr Avery encouraged members to publish their conference research and papers to make EAQUA more visible. themed "Habitat and paleoenvironmental reconstruction of pre-historic sites (paleobotany, isotopes, fauna and sedimentology)" Association (EAQUA) Conference was held in

The papers presented in sessions 1 and 2

and "Highland biodiversity and ecosystems", explored the proxies used in paleoclimate and paleoenvironmental reconstructions of prehistoric sites and different depositional environments and how they help with understanding the environmental context of evolution and adaptation and the dispersal of humans (Fig. 1). Sessions 3 and 4 on "Late Pleistocene-Holocene climate and rainfall variability, and human environment interactions" and "Global change impacts, adaptations and vulnerability assessment" focused on patterns and evidence of global change, and its effects on ecosystems, human populations and adaptation. Session 5 on "The quaternary fossil and archeological record" explored various fossil and archeological records from early Pleistocene and Holocene contexts to historic ones. Session 6 on "Heritage resource governance and sustainable development" showcased selected heritage resources, their vulnerabilities, enhanced management and conservation statuses, and their use as instruments for improving local community livelihoods and sustainable development.

During general discussion, plans for two possible collaborative research areas in carnivore ecology and heritage resource development were shared and interested researchers invited to take part.

At the EAQUA business meeting held at the end of the conference new executive members

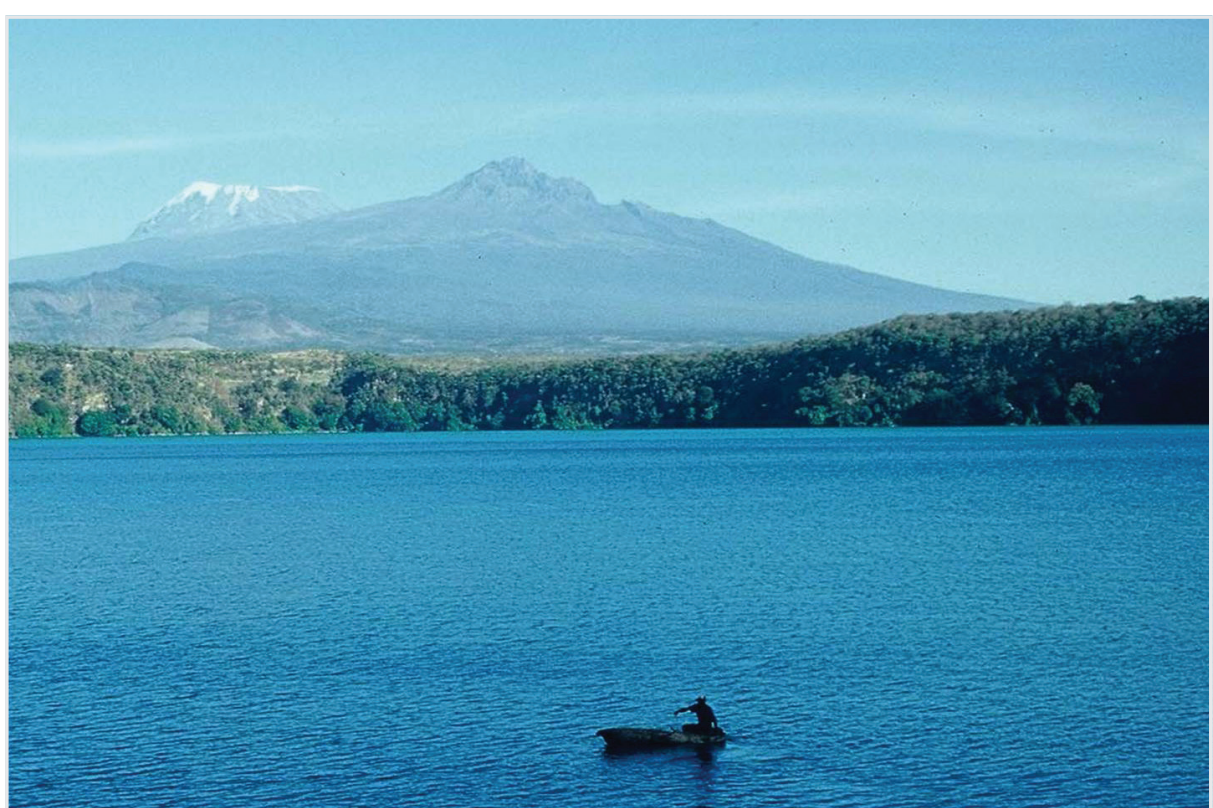

were elected and the following resolutions made:

- The EAQUA secretariat will work on various publicity and outreach programs to increase the membership base, including affiliation with similar research associations and reaching out to other eastern African countries not yet participating in EAQUA ac tivities e.g. South Sudan, Rwanda, Burundi, Eritrea, Djibouti and Somalia with the aim of mobilizing more researchers and students from eastern Africa to join the association.

- Set up a mentoring and capacity building program designed to be a pre-conference activity involving training on research, technical and logistical planning, grant applications as well as preparation of conference presentations and publications.

- Funds will be sourced for an EAQUA research program to include field training of students and young researchers.

-The local organizing committee and EAQUA secretariat will coordinate the publication of the current conference proceedings in Quaternary International.

- Members were urged to participate in the upcoming INQUA early career researchers and Pan African Quaternary research association workshops.

The participants elected Asfawossen Asrat as president, Christine Ogola as vice president, Morgan Andama as secretary general, Jackline Nyiracyiza as treasurer, Elgidius Ichumbaki as newsletter editor, Stephen Rucina and Pastory Bushozi as national representatives for Kenya and Tanzania, respectively, Alfred Muzuka as ex-officio member, and Margaret Avery as INQUA representative, for the next two years.

\section{AFFILIATIONS}

Archaeology Section, National Museums of Kenya, Nairobi, Kenya

\section{CONTACT}

Christine A. Ogola: cogola@gmail.com

\section{REFERENCES}

Moernaut J et al. (2010) Earth Planet Sci Lett 290: 214-223

Figure 1: Lake Chala southeast of Mt Kilimanjaro. Sediments from this lake are one of the longest archives of climate change in the region, reaching back at least 25,000 years (Moernaut et al. 2010). 